\title{
Synthesis and Electropolymerization of Phosphorylcholine- Containing Pyrroles and Their Hemocompatible Properties
}

\author{
Mikito Yasuzawa, ${ }^{\dagger}$ Takashi Matsuki, Tetsuya YAMAdA, and Akira KunUgi \\ Department of Chemical Science and Technology, Institute of Science and Technology, \\ The University of Tokushima, 2-1 Minamijosanjima, Tokushima 770-8506, Japan
}

\begin{abstract}
A series of $N$-substituted pyrroles having phosphorylcholine with different methylene chain lengths between pyrrole group and phosphorylcholine group were synthesized and their electropolymerizations were performed in aqueous solution. The methylene chains were trimethylene $(n=3)$, pentamethylene $(n=5)$, nonamethylene $(n=9)$, and undecamethylene $(n=11)$, for 3-(1-pyrrolyl)propyl-2-(trimethylammonium)ethyl phosphate (5a), 5-(1-pyrrolyl)pentyl2-(trimethylammonium)ethyl phosphate (5b), 9-(1-pyrrolyl)nonyl-2-(trimethylammonium)ethyl phosphate (5c), and 11-(1-pyrrolyl)undecyl-2-(trimethylammonium)ethyl phosphate (5d), respectively. Although electropolymerized films were produced from all pyrrole derivatives, thick and black polymer films were prepared from $\mathbf{5 a}, \mathbf{5 b}$ and $\mathbf{5} \mathbf{c}$. The pyrrole derivative with long methylene-chain $\mathbf{5 d}$ provided only colorless or slightly blackish thin film. Hemocompatibilities of the polymers from $\mathbf{5 a}, \mathbf{5 b}$ and $\mathbf{5 c}$ were evaluated by platelet rich plasma (PRP) contacting studies and scanning electron microscopy (SEM) observations. The results indicated that these polymers have excellent hemocompatibility.
\end{abstract}

(Received October 20, 2009; Accepted March 17, 2010; Published May 10, 2010)

\section{Introduction}

A great amount of interest has been paid to investigating the behavior of polymeric phospholipid analogues because phospholipids, together with protein, are a main component of biological membranes. Various studies have indicated that polymers bearing phosphatidylcholine analogues show excellent blood compatibility and these materials have become promising candidates for clinical trials..$^{1-15}$ On the other hand, the polymer electrodeposition technique is an excellent methods for preparing an ultrathin film that has controlled thickness. There is a growing interest in using electrochemically generated polymers, such as polypyrroles, in biosensor applications primarily as immobilization matrices because such allows the precise localization of enzymes and hence is ideal for enzyme deposition at miniature electrodes. ${ }^{16-26}$ It seemed attractive to prepare $\mathrm{N}$-substituted pyrrole polymers containing phosphatidylcholine, since the obtained electrogenerated film can be prospected to act as a hemocompatible material. The authors have reported that such pyrroles are useful for the immobilization of glucose oxidase (GOx) on platinum electrode and the obtained GOx-immobilized electrode functioned as a glucose sensor with good long-term stability. ${ }^{24}$ This paper is mainly concerned with the synthesis and properties of such polymers. The characterization of the polymers was based on their IR spectra and elemental analysis. The hemocompatibility of the synthesized polymers was evaluated by platelet-rich plasma contacting experiments and the results were observed by scanning electron microscopy (SEM) using unsubstituted polypyrrole as control.

† To whom correspondence should be addressed.

E-mail: mik@chem.tokushima-u.ac.jp

\section{Experimental}

\section{Materials}

$\mathbf{5 a}, \mathbf{5 b}, \mathbf{5 c}$, and $\mathbf{5 d}$ were prepared according to Scheme 1 .

2-Chloro-2-oxo-1,3,2-dioxaphospholane (1), bp $103.5-105.0^{\circ} \mathrm{C}$ (1 Torr) was prepared according to the method of Lucas et al. ${ }^{27}$ and Edmundson. ${ }^{28}$ 3-Amino-1-propanol (2a) and 5-amino-1-pentanol (2b) were commercially obtained and used without further purification. 9-Amino-1-nonanol (2c) and 11-amino-1-undecanol (2d) were prepared by a modification of the method of Ing et al. ${ }^{29}$ Tetrahydrofuran (THF) was distilled from lithium aluminum hydride. $N, N$-Dimethylformamide (DMF) was dehydrated over calcium hydride for 2 days and

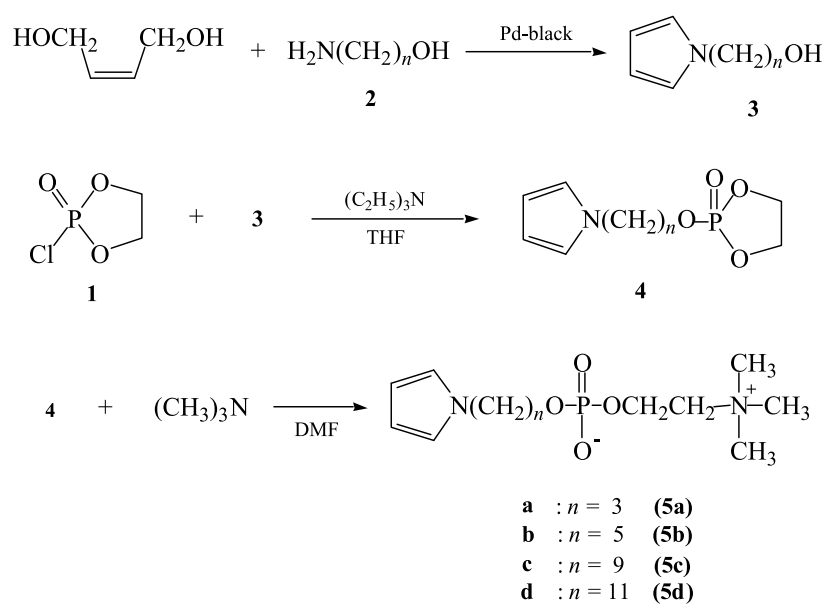

Scheme 1 General reaction route to synthesize $\mathbf{5 a}-\mathbf{5 d}$. 
then vacuum distilled. Anhydrous methanol was obtained by distillation in the presence of magnesium and a little iodine. Acetone was distilled from anhydrous potassium carbonate. Water was purified by double distillation of deionized water. Trimethylamine was prepared by the reaction of trimethylamine hydrochloride with $40 \%$ sodium hydroxide by the procedure of Adams and Brown. ${ }^{30}$

\section{Synthesis of 1-pyrrolylalkyl alcohol (3)}

3a - 3d were prepared according to a modification of the method of Murahashi ${ }^{31}$ by the reaction of $0.33 \mathrm{~mol}$ of 2 with $0.66 \mathrm{~mol}$ of cis-2-buten-1,4-diol, in the presence of $1 \mathrm{~g}$ of palladium black at $140^{\circ} \mathrm{C}$ for $24 \mathrm{~h}$. After the precipitate was filtered off and washed with $30 \mathrm{~cm}^{3}$ of dry methanol, the filtrate and the methanol solution were evaporated in vacuum. The residue was distilled under reduced pressure to obtain $\mathbf{3}$ as a colorless liquid.

3-(1-Pyrrolyl)propan-1-ol (3a): Product yield 72\%. bp $108^{\circ} \mathrm{C}$ (5 Torr).

5-(1-Pyrrolyl)pentan-1-ol (3b): Product yield 54\%. bp $118^{\circ} \mathrm{C}$ (5 Torr).

9-(1-Pyrrolyl)nonan-1-ol (3c): Product yield 50\%. bp $141^{\circ} \mathrm{C}$ (2 Torr).

11-(1-Pyrrolyl)undecan-1-ol (3d): Product yield 53\%. bp $167^{\circ} \mathrm{C}$ (4 Torr).

Synthesis of 2-pyrrolylalkyloxy-2-oxo-1,3,2-dioxaphospholane (4) In a thoroughly dried $300-\mathrm{cm}^{3}$ three-necked round bottomed flask equipped with a mechanical stirrer, drying tube, and dropping funnel were placed $25.7 \mathrm{mmol}$ of $\mathbf{3}$ and $51.4 \mathrm{mmol}$ of triethylamine in $200 \mathrm{~cm}^{3}$ of dry THF. After the solution was cooled in a dry ice/methanol bath $\left(-30^{\circ} \mathrm{C}\right), 25.7 \mathrm{mmol}$ of 1 were added slowly, and the triethylamine hydrochloride began to precipitate from the solution. The reaction mixture was maintained at -30 to $-20^{\circ} \mathrm{C}$ during the addition and then allowed to warm up to $-5^{\circ} \mathrm{C}$. After the mixture was kept at this temperature for $2 \mathrm{~h}$, the precipitate that formed was filtered off and washed with $30 \mathrm{~cm}^{3}$ of dry THF. The filtrate was concentrated on a rotary evaporator under reduced pressure to obtain $\mathbf{4}$ in quantitative yield as a pale yellow viscous liquid.

Synthesis of (1-pyrrolyl)alkyl-2-(trimethylammonium)ethyl phosphate (5)

The synthesis was carried out according to the method of Thoung and Chabrier. ${ }^{32}$ A typical preparation procedure of 5: in a $300-\mathrm{cm}^{3}$ glass pressure bottle (Top Model E 1435 Type A) were placed $25.5 \mathrm{mmol}$ of 4 and $100 \mathrm{~cm}^{3}$ of dry DMF. After the pressure bottle was cooled in ice-water, $0.106 \mathrm{~mol}$ of trimethylamine was rapidly added to the cooled solution. The pressure bottle was closed and then shaken in a thermostat maintained at $60^{\circ} \mathrm{C}$ for $24 \mathrm{~h}$. After it had been allowed to cool to $0^{\circ} \mathrm{C}$, a pale yellow, transparent, and viscous product was precipitated. The precipitate was filtered and dissolved in dry methanol, and then it was reprecipitated from acetone. This operation was repeated three times to obtain $\mathbf{5}$ as a hygroscopic pale yellow solid.

3-(1-Pyrrolyl)propyl-2-(trimethylammonium)ethyl phosphate (5a). Product yield $47 \%$. mp $160^{\circ} \mathrm{C}$.

${ }^{1} \mathrm{H}$ NMR $\left(\mathrm{CD}_{3} \mathrm{OD}\right): \mathrm{d}=2.05\left(\mathrm{~m} ; 2 \mathrm{H},-\mathrm{CH}_{2} \mathrm{CH}_{2} \mathrm{CH}_{2}-\right), 3.15$ (s; $\left.9 \mathrm{H}, \quad-\mathrm{N}^{+}\left(\mathrm{CH}_{3}\right)_{3}\right), \quad 3.65-4.15 \quad\left(\mathrm{~m} ; \quad 8 \mathrm{H}, \quad \mathrm{POCH}_{2} \mathrm{CH}_{2} \mathrm{~N}^{+}\right.$, $>\mathrm{NC}_{2} \underline{\mathrm{C}}_{2} \underline{\mathrm{CH}}_{2} \mathrm{O}$ ), 5.95 (t; $\left.2 \mathrm{H}, \mathrm{Py}_{3}, 4\right)$, and $6.65 \mathrm{ppm}(\mathrm{t} ; 2 \mathrm{H}$, $\mathrm{Py} \underline{\mathrm{H}}_{2,5}$ ).

$\mathrm{C}_{12} \mathrm{H}_{23} \mathrm{~N}_{2} \mathrm{O}_{4} \mathrm{P}_{1} \cdot 3 \mathrm{H}_{2} \mathrm{O}(344.33)$

$\begin{array}{llll}\text { Calc. }(\%) & \text { C } 41.86 & \text { H } 8.49 & \text { N 8.14\% } \\ \text { Found (\%) } & \text { C } 42.47 & \text { H } 8.23 & \text { N 7.86\% }\end{array}$

5-(1-Pyrrolyl)pentyl-2-(trimethylammonium)ethyl phosphate (5b).

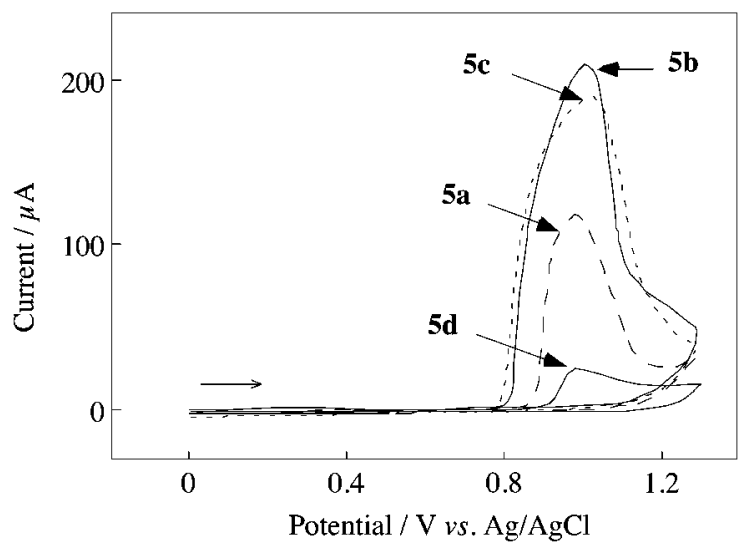

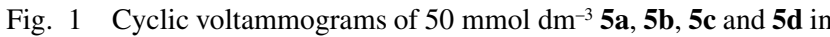
water containing $0.1 \mathrm{~mol} \mathrm{dm}^{-3} \mathrm{LiClO}_{4}$. The sweep rate was $0.05 \mathrm{~V} \mathrm{~s}^{-1}$.

Product yield $51 \%$. mp $200^{\circ} \mathrm{C}$.

$\mathrm{C}_{14} \mathrm{H}_{27} \mathrm{~N}_{2} \mathrm{O}_{4} \mathrm{P}_{1} \cdot \mathrm{H}_{2} \mathrm{O}$ (336.36)

$\begin{array}{llll}\text { Calc. }(\%) & \text { C } 41.86 & \text { H } 8.49 & \text { N 8.14\% } \\ \text { Found (\%) } & \text { C } 42.47 & \text { H } 8.23 & \text { N 7.86\% }\end{array}$

9-(1-Pyrrolyl)nonyl-2-(trimethylammonium)ethyl phosphate (5c). Product yield $73 \%$. $\mathrm{mp} 225^{\circ} \mathrm{C}$.

$\mathrm{C}_{18} \mathrm{H}_{35} \mathrm{~N}_{2} \mathrm{O}_{4} \mathrm{P}_{1} \cdot 2 \mathrm{H}_{2} \mathrm{O}(410.48)$

$\begin{array}{llll}\text { Calc. }(\%) & \text { C } 52.67 & \text { H } 9.58 & \text { N } 6.82 \% \\ \text { Found (\%) } & \text { C } 51.98 & \text { H } 9.07 & \text { N 6.69\% }\end{array}$

11-(1-Pyrrolyl)undecyl-2-(trimethylammonium)ethyl phosphate (5d). Product yield $71 \%$. mp $256^{\circ} \mathrm{C}$.

$\mathrm{C}_{20} \mathrm{H}_{39} \mathrm{~N}_{2} \mathrm{O}_{4} \mathrm{P}_{1} \cdot 2 \mathrm{H}_{2} \mathrm{O}(438.53)$

$\begin{array}{llll}\text { Calc. (\%) } & \text { C } 54.78 & \text { H } 9.88 & \text { N } 6.39 \% \\ \text { Found (\%) } & \text { C } 55.20 & \text { H } 9.40 & \text { N } 6.67 \%\end{array}$

\section{Polymer film preparation}

Electrochemical polymerization of $\mathbf{5}$ was performed in a one-compartment cell at $4^{\circ} \mathrm{C}$ with an ITO $(2.0 \times 1.0 \mathrm{~cm})$ working electrode, an $\mathrm{Ag} / \mathrm{AgCl}$ reference electrode and a platinum flag counter electrode. Polymer films were grown from a deaerated aqueous solution containing $0.2 \mathrm{~mol} \mathrm{dm}^{-3}$ of 5 and $0.1 \mathrm{~mol} \mathrm{dm}^{-3}$ of $\mathrm{LiClO}_{4}$. A constant potential of $1.20 \mathrm{~V}$ (vs. $\mathrm{Ag} / \mathrm{AgCl}$ ) was applied and the amount of deposition charge passed was $7 \mathrm{mC} \mathrm{mm}^{-2}$. The electrodes covered with the polymer film were then rinsed with water, and the polymer film was torn off from the ITO electrode using forceps. The polymer film was washed with water and dried in air for at least $48 \mathrm{~h}$.

\section{Hemocompatibility evaluation}

The control, unsubstituted polypyrrole film, was prepared by applying a potential of $1.2 \mathrm{~V}(v s . \mathrm{Ag} / \mathrm{AgCl})$ to an ITO electrode in an acetonitrile solution containing $0.06 \mathrm{~mol} \mathrm{dm}^{-3}$ pyrrole, $0.1 \mathrm{~mol} \mathrm{dm}^{-3}$ of $\mathrm{LiClO}_{4}$ and $1 \% \mathrm{H}_{2} \mathrm{O}$ at $25^{\circ} \mathrm{C}$. Polymer film and unsubstituted polypyrrole films were washed with saline solution and incubated at $37^{\circ} \mathrm{C}$ for $60 \mathrm{~min}$ with freshly prepared PRP (platelet rich plasma) which was obtained from the centrifugation of human blood at $1000 \mathrm{rpm}$ for $20 \mathrm{~min}$. The samples were rinsed with saline and treated with $2.5 \%$ glutaraldehyde in saline and maintained at $4{ }^{\circ} \mathrm{C}$ overnight. This treatment fixed all platelets attached to the surface of the polymer. The samples were then rinsed with saline and dehydrated by systematic immersion in a series of ethanol-water solutions: $60,70,80,90$, and $100 \%$ v/v. Following critical point drying with $\mathrm{CO}_{2}$, the samples were coated with gold prior to being observed in a SEM. 

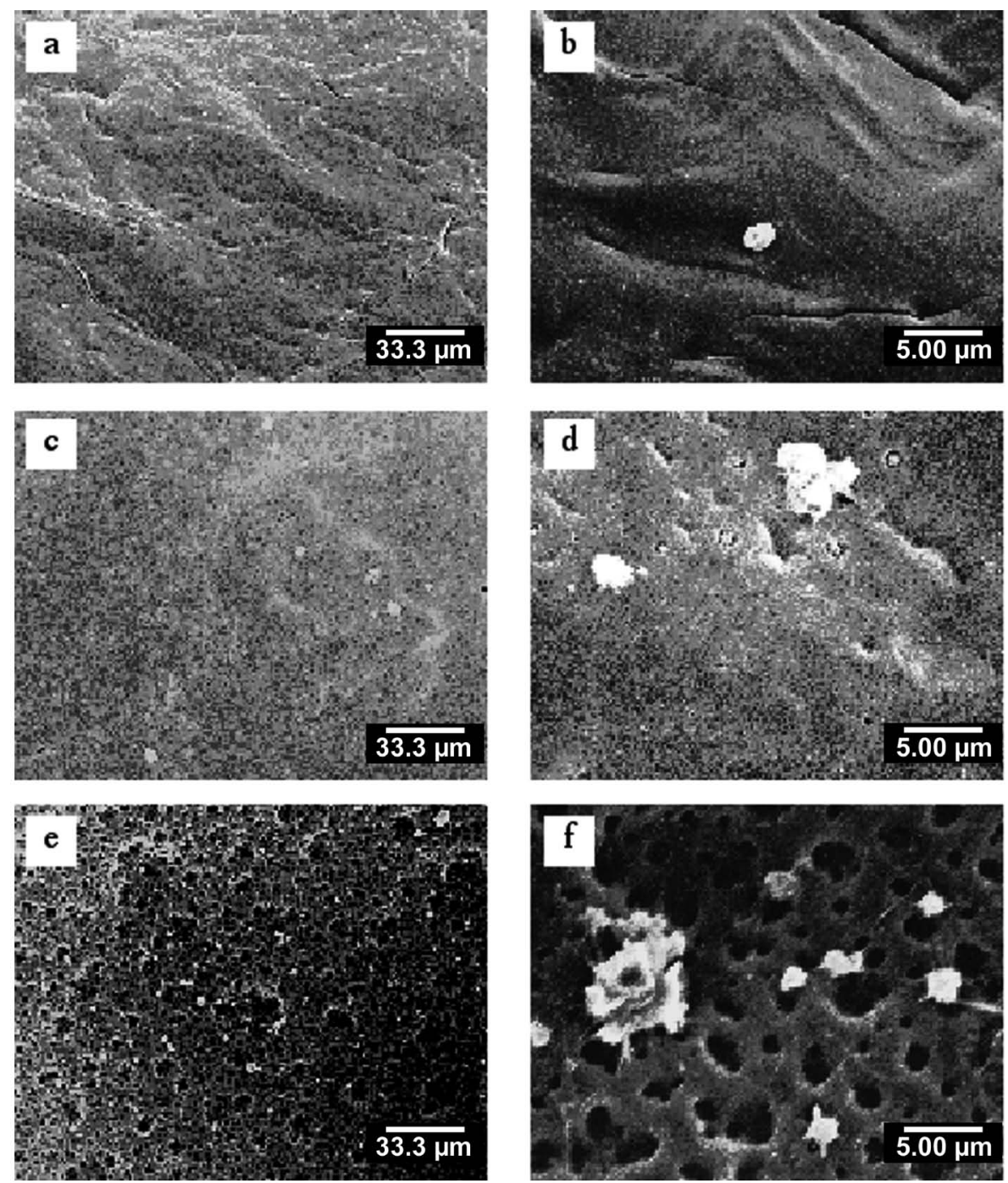

Fig. 2 SEM photographs of the surface of polymer film from $\mathbf{5 b}$ (a and b), $\mathbf{5 c}$ (c and d), and polypyrrole film (e and f) after contact with human PRP for $60 \mathrm{~min}$. Actual magnification: (a, c, and e) $\times 300$; $(\mathrm{b}, \mathrm{d}$, and $\mathrm{f}) \times 2000$.

\section{Measurements}

${ }^{1} \mathrm{H}$ NMR measurement was carried out on a $60 \mathrm{MHz}$ Hitach-Perkin Elmer Model R-20 NMR spectrometer. Proton chemical shifts, reported in parts per million, were referenced to trimethylsilane directly as an internal standard. Multiplicities of resonance peaks are indicated as singlet (s), triplet (t) and multiplet $(\mathrm{m})$. Polarizing optical microscopy was carried out with a Yanaco Model MP heating stage.

All electrochemical studies were carried out using a Bioanalytical Systems, Inc., BAS 100B.

\section{Results and Discussion}

\section{Electrochemical behavior of pyrrole derivatives}

The cyclic voltammograms of $\mathbf{5 a}, \mathbf{5 b}, \mathbf{5 c}$, and $\mathbf{5 d}$ in aqueous solution containing $0.1 \mathrm{~mol} \mathrm{dm}{ }^{-3} \mathrm{LiClO}_{4}$ are shown in Fig. 1 . An irreversible single oxidation peak was observed at approximately $1.1 \mathrm{~V}$ (vs. $\mathrm{Ag} / \mathrm{AgCl})$ on the first scan. The electropolymerization potentials of these pyrrole derivatives were slightly more positive than that of unsubstituted pyrrole. Considering that the smaller pyrroles with shorter methylene chain gain an advantage in diffusion over larger pyrroles with longer methylene chain, one can conclude that the oxidation peak current corresponding to the polymerization of pyrrole will be higher for a shorter methylene chain pyrrole. Nevertheless, the oxidation peak current of $\mathbf{5 b}$ and $\mathbf{5} \mathbf{c}$ were higher than that of shorter 5a. One possible explanation for this phenomenon is the existence of $N$-subsituent terminal bulky phosphorylcholine group, which may influence the electroconductivity of the obtained polypyrrole, since the electrooxidation of pyrroles can also take place on the surface of electroconductive polypyrrole. On the other hand, the formation of polymer films with low electroconductivity will reduce the electroactive surface area and the diffusion of pyrrole to the electrode. In order to generate polypyrrole with high electroconductivity, the planar structure arrangement of the $\pi$-conjugated pyrrole rings is essential. However, the existence of a bulky substituent close to the pyrrole ring may interrupt the planar structure because of the stereoscopic hindrance. Therefore, it is reasonable that the separation of the pyrrole ring and the bulky group by the introduction of methylene chain with certain length relieves the hindrance to form a planar structure of the pyrrole rings, which leads to an increase of electroconductivity of the polymer. 

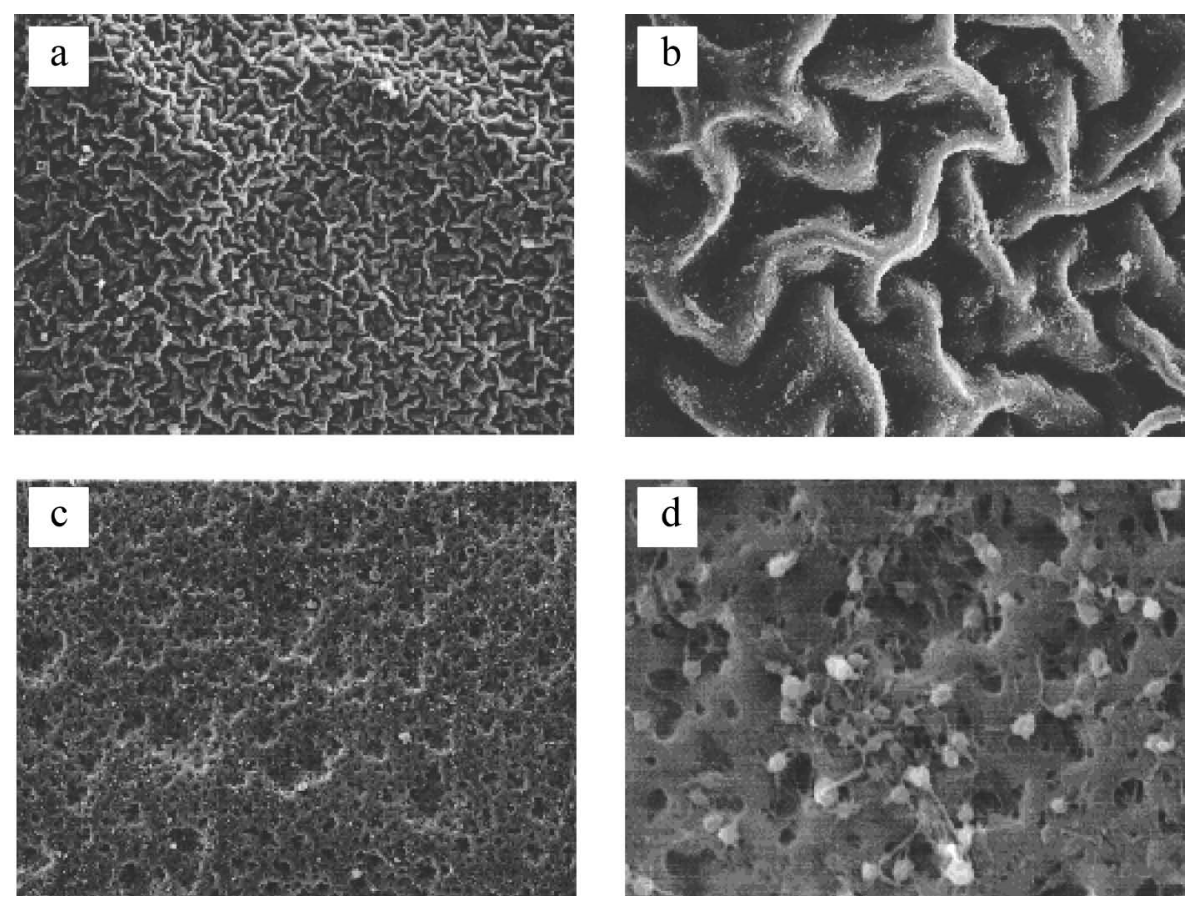

Fig. 3 SEM photographs of the surface of polymer film from $\mathbf{5 a}$ (a and b) and polypyrrole film (c and d) after contact with human PRP for 60 min. Actual magnification: (a and c) $\times 300$; (b and d) $\times 2000$.

Similar phenomena were observed on a GOx immobilized electrode prepared by the electropolymerization of pyrrole derivatives containing a gluconyl- and osmium bipyridine complex with a methylene-terminal group introduced at the 1-position. ${ }^{25,26}$

A constant potential of $1.20 \mathrm{~V}(v s . \mathrm{Ag} / \mathrm{AgCl})$ was applied for the electropolymerization of all pyrrole derivatives. After a deposition charge of $7 \mathrm{mC} \mathrm{mm}^{-2}$ was passed, black thick films were obtained on the surface of the electrode for $\mathbf{5 a}, \mathbf{5 b}$ and $\mathbf{5 c}$, while $\mathbf{5 d}$ provided only colorless thin film. Attempts to produce black thick film from $\mathbf{5 d}$ by further electropolymerization were fruitless, since the oxidation current was significantly lowered. The obtained polymers were insoluble in water, methanol, ethanol, acetone, and ether.

\section{Hemocompatibility evaluation}

The appearance of platelets on the material surface after exposing it to PRP is effective to evaluate the hemocompatibility, since platelet adsorption is an important step for the formation of thrombus. The polymer films were incubated in human PRP for $60 \mathrm{~min}$, and each observed using SEM. Figure 2 shows typical SEM photographs of the surface of the polymer film from $\mathbf{5 b}, \mathbf{5 c}$ and reference unsubstituted polypyrrole film. No differences between the results of $\mathbf{5 b}$ and $\mathbf{5 c}$ polymer films were observed, i.e. very few platelets were adhered and the variation in their shape was very limited. On the other hand, unsubstituted polypyrrole film not only had a large number of platelets but also the shapes of the adhered platelets greatly changed. Based on the SEM observation, the number of adhered platelets in an area of $0.1 \mathrm{~mm} \times 0.1 \mathrm{~mm}$ was less than one for polymer film for both $\mathbf{5 b}$ and $\mathbf{5 c}$, whereas it was more than 20 for unsubstituted polypyrrole film. Similar results were obtained by the measurement performed on 5a polymer film (Fig. 3). Although numerous wrinkles were observed all over the film, the amount of platelets adhered was quite limited (Figs. 3(a) and 3(b)).
Wrinkles generated in 5a film were due to its high swelling property in water. Polymer film of $\mathbf{5 d}$ was not evaluated, since the obtained film was not thick enough to be removed from the substrate. The results further confirm that polymer films from $\mathbf{5 a}, \mathbf{5 b}$ and $\mathbf{5 c}$ have excellent hemocompatibility.

\section{Conclusions}

A series of pyrrole derivatives containing phosphatidylcholine moieties were synthesized and electrochemically polymerized in aqueous solution. The preliminary results suggest that the polypyrroles containing phosphatidylcholine moiety may be regarded as hopeful biomaterials for their favorable blood compatibilities. These new polypyrroles may be useful in wide bioapplications as coating or structural materials for blood-contacting medical instruments such as implantable biosensors, pacemaker lead wire insulation, stents and catheters.

\section{References}

1. Y.-J. Li, R. Bahulekar, Y.-F. Wang, T.-M. Chen, M. Kitamura, M. Kodama, and T. Nakaya, J. Biomater. Sci., Polym. Ed., 1996, 7, 893.

2. K. Ishihara, Trends Polym. Sci., 1997, 5, 401.

3. K. Ishihara, H. Nomura, T. Mihara, K. Kurita, Y. Iwasaki, and N. Nakabayashi, J. Biomed. Mater. Res., 1998, 39, 323.

4. T. Tomita, Y.-J. Li, and T. Nakaya, Chem. Mater., 1999, 11, 2155.

5. T. Nakaya and Y.-J. Li, Prog. Polym. Sci., 1999, 24, 143.

6. T. Nakaya and Y.-J. Li, Recent Res. Develop. Polym. Sci., 2000, 4, 53.

7. A. Korematsu, Y. Takemoto, T. Nakaya, and H. Inoue, Biomaterials, 2002, 23, 263. 
8. T. Nakaya and Y.-J. Li, Des. Monomers Polym., 2003, 6, 309.

9. T. Uchiyama, J. Watanabe, and K. Ishihara, J. Biomater. Sci. Polym. Ed., 2004, 15, 1237.

10. Y. Iwasaki and K. Ishihara, Anal. Bioanal. Chem., 2005, 381, 534.

11. T. Kihara, N. Yoshida, S. Mieda, K. Fukazawa, C. Nakamura, K. Ishihara, and J. Miyake, NanoBiotechnology, 2007, 3, 127.

12. J. Watanabe and K. Ishihara, Colloids Surf., B, 2008, 65, 155.

20. W. Schuhmann, Mikrochim. Acta, 1995, 121, 1.

21. B. D. Malhotra, A. Chaubey, and S. P. Singh, Anal. Chem. Acta, 2006, 578, 59.

22. T. Ahuja, I. A. Mir, D. Kumar, and Rajesh, Biomaterials, 2007, 28, 791.

23. R. E. Ionescu, S. Cosnier, S. Herrmann, and R. S. Marks, Anal. Chem., 2007, 79, 8662.

24. M. Yasuzawa, T. Matsuki, H. Mitsui, A. Kunugi, and T. Nakaya, Sens. Actuators, B, 2000, 66, 25.

25. M. Yasuzawa, S. Fujii, A. Kunugi, and T. Nakaya, Anal. Sci., 1999, 15, 1175.

13. C. Susin, M. Qahash, J. Hall, L. Sennerby, and U. M. E. Wikesjo, J. Clin. Periodontol., 2008, 35, 270.

14. J. Choi, T. Konno, R. Matsuno, M. Takai, and K. Ishihara, Colloids Surf., B, 2008, 67, 216.

15. H. Chen, L. Yuan, W. Song, Z. Wu, and D. Li, Prog. Polym. Sci., 2008, 33, 1059.

16. M. Umaña and J. Waller, Anal. Chem., 1986, 58, 2979.

17. N. C. Foulds and C. R. Lowe, J. Chem. Soc., Faraday Trans. 1, 1986, 82, 143.

18. B. F. Y. Yon-Hin, R. S. Sethi, and C. R. Lowe, Sens. Actuators, B, 1990, 1, 537.

19. B. F. Y. Yon-Hin and C. R. Lowe, J. Electroanal. Chem., 1994, 374, 167.

26. M. Tsujimoto, T. Yabutani, A. Sano, Y. Tani, H. Murotani, Y. Mishima, K. Maruyama, M. Yasuzawa, and J. Motonaka, Anal. Sci., 2007, 23, 59.

27. H. Lucas, F. W. Mitchell, and C. N. Scully, J. Am. Chem. Soc., 1950, 72, 5491.

28. R. E. Edmundson, Chem. Ind., 1962, 1828.

29. H. R. Ing and R. H. F. Manske, J. Chem. Soc., 1926, 2348.

30. R. Adams and T. K. Brown, "Organic Syntheses", 1943, Collect. Vol. I, Wiley, New York, 528.

31. S.-I. Murahashi, T. Shimamura, and L. Moritani, Chem. Commun., 1974, 931.

32. N. T. Thoung and P. Chabrier, Bull. Soc. Chim. Fr., 1974, 667. 